\title{
Outcomes Article
}

\section{Prospective Analysis of Primary Breast Augmentation on Body Image Using the BREAST-Q: Results from a Nationwide Study}

Amy Alderman, M.D., M.P.H.

Andrea Pusic, M.D., M.H.S. Diane K. Murphy, M.B.A.

Alpharetta, Ga.; New York, N.Y.; and Irvine, Calif.

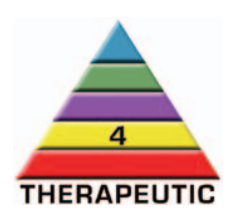

Background: The Breast Implant Follow-up Study is a large, ongoing observational study of women who received Natrelle round silicone-filled or salinefilled breast implants. This analysis describes patient-reported outcomes in the cohort who underwent breast augmentation.

Methods: Subjects prospectively completed two validated scales of the BREAST-Q (satisfaction with breasts and psychosocial well-being) preoperatively and at 1 and 4 years postoperatively. Effect size and $z$ tests were used to compare differences between preoperative versus postoperative scores; multivariate mixed models were used to compare differences in scores between silicone-filled and saline-filled implants.

Results: Of 17,899 subjects completing the BREAST-Q preoperatively, 14,514 (81.1 percent) completed the postoperative questionnaire $(12,726$ received silicone-filled implants and 1788 received saline-filled implants). Overall, satisfaction with breasts and psychosocial well-being increased significantly at postoperative year 1 ( $p<0.0001$ for both), and the improvement was sustained at year 4 ( $p<0.0001$ for both). Large effect sizes were observed for satisfaction with breasts (2.0 at year $1 ; 1.8$ at year 4$)$ and psychosocial well-being (1.2 at year $1 ; 1.0$ at year 4$)$. In the multivariate model, silicone-filled implants were associated with significantly greater improvement compared with saline-filled implants for satisfaction with breasts and psychosocial well-being at year 1 ( $p<0.0001$ for both) and year 4 ( $p<0.0001$ and $p<0.0019$, respectively).

Conclusions: Breast implants are effective in improving women's quality of life. The authors found significant and sustained improvements in satisfaction and psychosocial well-being in women undergoing breast augmentation with Natrelle silicone-filled or saline-filled implants. (Plast. Reconstr. Surg. 137: 954e, 2016.)

CLINICAL QUESTION/LEVEL OF EVIDENCE: Therapeutic, IV.
B reast augmentation is the most common cosmetic surgical procedure in the United States, with nearly 300,000 procedures

From the Swan Center for Plastic Surgery; Memorial Sloan Kettering Cancer Center; and Allergan, Inc.

Received for publication June 22, 2015; accepted January 21, 2016.

This trial is registered under the name "Safety Follow-up Study in Subjects With Silicone Gel-filled Breast Implants as Compared Both to Saline-filled Breast Implants and to National Norms (BIFS)," Clinical Trials.gov identification number NCTO0443274 (https://clinicaltrials.gov/ct2/ show/NCT00443274).

Copyright (c) 2016 by the American Society of Plastic Surgeons. This is an open-access article distributed under the terms of the Creative Commons Attribution-Non CommercialNo Derivatives License 4.0 (CCBY-NC-ND), where it is permissible to download and share the work provided it is properly cited. The work cannot be changed in any way or used commercially.

DOI: $10.1097 /$ PRS.0000000000002183 performed annually. ${ }^{1}$ Traditionally, outcomes following breast augmentation have been evaluated from the surgeon's perspective, including short-term and long-term complication rates and aesthetic outcomes. However, outcomes following breast augmentation should also be considered from the patient's perspective, which may differ considerably from that of the surgeon. Importantly, patients in numerous studies have

Disclosure: Dr. Alderman is a consultant for Mentor, Inc., and is a member of their Breast Reconstruction Advisory Committee. Dr. Pusic is co-developer of the BREAST-Q, which is owned by Memorial Sloan Kettering Cancer Center, and receives royalty payments when the BREAST-Q is used in industrysponsored clinical trials. Dr. Murphy is an employee and stockholder of Allergan, Inc. This study was sponsored by Allergan. 
reported improved quality of life, better psychosocial and sexual well-being, and greater satisfaction with breast appearance following breast augmentation. ${ }^{2-6}$

With the approval of silicone gel-filled breast implants in the United States in 2006, the U.S. Food and Drug Administration required manufacturers to conduct postapproval studies to evaluate the performance and safety of these devices over a 10-year period. ${ }^{7}$ The Breast Implant Follow-Up Study (BIFS-001) is a large, ongoing observational study designed to address this U.S. Food and Drug Administration requirement for Natrelle silicone gel-filled breast implants (Allergan, Inc., Irvine, Calif.). Natrelle breast implants are constructed with a low-diffusion silicone elastomer shell and are filled with a soft, cohesive silicone gel. They are available in a range of implant options, including smooth shell and Biocell textured shell surfaces, and are approved by the U.S. Food and Drug Administration for primary breast augmentation, primary breast reconstruction, and revision surgery after either of these procedures. ${ }^{8}$ The present analysis describes patient-reported outcomes in women enrolled in the Breast Implant FollowUp Study who underwent primary breast augmentation with Natrelle round silicone-filled breast implants compared with saline-filled implants. The BREAST-Q (Mapi Research Trust; Lyon, France), a validated patient-reported outcome measure, ${ }^{9,10}$ was used to evaluate changes in body image over time and by implant type.

\section{PATIENTS AND METHODS}

\section{Study Design}

The Breast Implant Follow-Up Study is a large, multicenter, 10-year observational study that compares outcomes in women receiving Natrelle silicone-filled breast implants with those receiving saline-filled breast implants. After the study began, the protocol was amended to include BREAST-Q assessments. Women were screened for eligibility after deciding to undergo breast implantation and completed baseline assessments before surgery. For continued participation, subjects must have received unilateral or bilateral (either both silicone or both saline) Natrelle round siliconefilled implants or saline-filled implants. Follow-up BREAST-Q questionnaires are administered by means of the Internet, telephone interview, or mail at years 1, 4, and 10 of the study. For those receiving the silicone-filled implants, a physical examination was performed at postoperative years 1,4 , and 10 to assess for local complications. This study received approval from the institutional review board at each investigational site and is being conducted in accordance with Good Clinical Practice guidelines and World Health Organization guidelines. All subjects provided written informed consent before undergoing any study-related procedure.

\section{Subjects}

The present analysis includes only women who underwent primary breast augmentation and completed the BREAST-Q at baseline, before implantation. Women aged 22 years and older who were candidates for breast augmentation with Natrelle silicone-filled implants or saline-filled implants at the time of surgery were eligible if they were fluent in English or Spanish. The incision site (e.g., inframammary, periareolar, axillary, mastopexy incision, or mastectomy scar) and implant location (e.g., submuscular or subglandular) were at the discretion of the investigator and were not used in determining a subject's study eligibility. Subjects were excluded if they were transgender or, if receiving a saline implant, had a current or previous unilateral or bilateral silicone breast implant. Subjects deemed by the investigator to be unsuitable candidates for long-term follow-up were also excluded.

\section{Effectiveness}

The effectiveness of primary augmentation on patient-reported outcomes was assessed using two previously validated BREAST-Q scales measuring body image (satisfaction with breasts and psychosocial well-being). ${ }^{9}$ The BREAST-Q was administered preoperatively when women who decided to undergo breast implantation agreed to participate in the study and postoperatively at years 1 and 4 by means of the Internet, a telephone interview, or postal mail. The BREAST-Q has a modular, procedure-specific structure; the module for breast augmentation was used in this study. The BREAST-Q scales were previously shown to be reliable and valid. ${ }^{9}$ For scales constituting the augmentation module, internal consistency measured by Cronbach $\alpha$ ranged from 0.81 to 0.94 and item-total correlation ranged from 0.55 to 0.82 . Test-retest reliability determined by intraclass correlation coefficients ranged from 0.85 to $0.94 .^{9}$ Satisfaction with breasts was evaluated preoperatively using a six-item scale that focused on issues related to breast appearance, size, and amount of cleavage; and postoperatively using a 17-item scale that focused on issues related to 
Plastic and Reconstructive Surgery • June 2016

breast appearance, softness, size, amount of cleavage, scar appearance, and extent of implant rippling. Each item was scored on a four-point scale ( 1 = very dissatisfied, 2 = somewhat dissatisfied, $3=$ somewhat satisfied, and $4=$ very satisfied). Psychosocial well-being was assessed preoperatively and postoperatively using a nine-item scale focusing on issues such as confidence in social settings, feeling attractive, self-assurance, and self-confidence. Each item was scored on a five-point scale $(1=$ none of the time, $2=$ a little of the time, $3=$ some of the time, $4=$ most of the time, and $5=$ all of the time).

\section{Statistical Analysis}

The satisfaction with breasts and psychosocial well-being scales on the BREAST-Q were scored separately. Each score was transformed to a 0 - to 100-point scale using a conversion table provided with the BREAST-Q. ${ }^{10}$ Higher scores indicate a better patient-reported outcome. Differences in preoperative versus postoperative mean scores were evaluated using effect size calculations. Effect size was calculated as the difference between the preoperative and postoperative mean values, divided by the preoperative standard deviation. ${ }^{11}$ Changes from baseline were tested using the $z$ test (i.e., the probability that the effect size, $z$, is 0 assuming a normal distribution). The magnitude of the effect size was determined using Cohen's arbitrary criteria ( 0.2 for small, 0.5 for moderate, and 0.8 for large).$^{5,12}$

Multivariate mixed models were used to compare improvements in BREAST-Q scales between the cohorts receiving silicone-filled versus saline-filled implants. All models were run using SAS statistical software (SAS Institute, Inc., Cary, N.C.) using the GLIMMIX procedure, ${ }^{13}$ with subject as a random effect, an identity link function, normal distribution of error, and compound symmetry covariance matrix. Differences between groups (silicone versus saline implants) and associated $p$ values were reported using least squares means. For satisfaction with breasts, the model adjusted for baseline score, age, body mass index greater than or equal to $25 \mathrm{~kg} / \mathrm{m}^{2}$, marital status, smoking status, race, incision site, and thoughts about suicide before baseline. For psychosocial wellbeing, the model adjusted for baseline score, race, body mass index greater than or equal to $25 \mathrm{~kg} / \mathrm{m}^{2}$, marital status, substance abuse status, incision site, implant location, and thoughts about suicide before baseline.

\section{RESULTS}

\section{Subjects}

The Breast Implant Follow-Up Study enrolled 56,616 eligible subjects from February of 2007 through March of 2010 at 1116 sites. A total of 44,007 subjects in the Breast Implant Follow-Up Study underwent primary breast augmentation. Of these, 29,751 women (67.6 percent) received Natrelle silicone-filled breast implants and 14,256 (32.4 percent) received saline-filled breast implants. The analysis of the BREAST-Q data focused on 17,899 subjects with preoperative baseline data and at least one postsurgical assessment, who entered the study at or after the time of the protocol amendment authorizing administration of the BREAST-Q. Of these, 14,514 subjects (81.1 percent) completed questionnaires at baseline and after baseline, including 12,726 women who received silicone-filled implants and 1788 women who received saline-filled implants.

The demographic characteristics of the silicone-filled and saline-filled implant groups are listed in Table 1. Overall, the median age was 34 years (range, 22 to 75 years), and the majority of subjects (77.0 percent) were white. The mean body mass index was $22.0 \mathrm{~kg} / \mathrm{m}^{2}$, with 14.0 percent of subjects having a body mass index greater than or equal to $25 \mathrm{~kg} / \mathrm{m}^{2}$. The group receiving Natrelle silicone-filled implants was significantly older, included a higher proportion of white subjects and a lower proportion of Hispanic subjects, and had a lower proportion of subjects with a body mass index greater than or equal to $25 \mathrm{~kg} / \mathrm{m}^{2}$ $(p<0.0001$ for all $)$. In terms of lifestyle characteristics, smoking history and alcohol consumption differed significantly between the 2 groups $(p<0.0001$ for both) (Table 2$)$. A smaller proportion of subjects receiving Natrelle silicone-filled implants were current smokers, but a larger proportion consumed alcohol on a weekly or daily basis compared with subjects receiving saline implants. Overall, 78.9 percent of subjects reported having ever been pregnant (mean, 2.6 pregnancies) and 77.4 percent of subjects had attempted to breast-feed. Both factors, previous pregnancy (79.2 percent versus 76.5 percent; $p=0.009$ ) and having attempted to breast-feed (78.2 percent versus 72.1 percent; $p<0.0001$ ), were reported more frequently by women receiving the silicone-filled implants compared with those receiving saline-filled implants.

\section{Implants}

A total of 25,420 Natrelle silicone-filled implants and 3571 saline-filled implants were used in the breast augmentation procedures (Table 3). Overall, most

\section{$956 e$}


Volume 137, Number 6 • Breast Augmentation and Body Image

Table 1. Subject Demographics

\begin{tabular}{|c|c|c|c|}
\hline Parameter & $\begin{array}{l}\text { Silicone-Filled } \\
\text { Implants (\%) }\end{array}$ & $\begin{array}{c}\text { Saline-Filled } \\
\text { Implants (\%) }\end{array}$ & $p^{*}$ \\
\hline No. & 12,726 & 1788 & \\
\hline \multicolumn{4}{|l|}{ Age, yr } \\
\hline Median & 34 & 32 & \multirow{9}{*}{$<0.0001$} \\
\hline Range & $22-75$ & $22-75$ & \\
\hline \multicolumn{3}{|l|}{ Age distribution } & \\
\hline $22-29$ yr & 3955 (31.1) & 714 (39.9) & \\
\hline $30-39$ yr & $5010(39.4)$ & $681(38.1)$ & \\
\hline $40-49 \mathrm{yr}$ & $2783(21.9)$ & 299 (16.7) & \\
\hline $50-59 \mathrm{yr}$ & $836(6.6)$ & $83(4.6)$ & \\
\hline $60-69 \mathrm{yr}$ & $129(1.0)$ & $9(0.5)$ & \\
\hline$\geq 70 \mathrm{yr}$ & $13(0.1)$ & $2(0.1)$ & \\
\hline $\begin{array}{l}\text { Mean BMI } \pm \\
\text { SD }, \mathrm{kg} / \mathrm{m}^{2}\end{array}$ & $21.9 \pm 3.0$ & $22.6 \pm 3.3$ & \multirow[t]{2}{*}{$<0.0001$} \\
\hline $\mathrm{BMI} \geq 25 \mathrm{~kg} / \mathrm{m}^{2}$ & $1658(13.0)$ & $381(21.4)$ & \\
\hline \multicolumn{3}{|l|}{ Race/ethnicity } & \multirow[t]{7}{*}{$<0.0001$} \\
\hline White & $9869(77.5)$ & $1312(73.4)$ & \\
\hline Hispanic & $1391(10.9)$ & $261(14.6)$ & \\
\hline Asian & $694(5.5)$ & $81(4.5)$ & \\
\hline Black & $265(2.1)$ & $61(3.4)$ & \\
\hline Other & $427(3.4)$ & $65(3.6)$ & \\
\hline Unknown & $80(0.6)$ & $8(0.4)$ & \\
\hline \multicolumn{3}{|l|}{ Marital status } & \multirow{10}{*}{0.0762} \\
\hline Married & 7147 (56.2) & $957(53.5)$ & \\
\hline \multicolumn{3}{|l|}{$\begin{array}{l}\text { Single, never } \\
\text { married }\end{array}$} & \\
\hline Divorced & $1830(14.4)$ & $264(14.8)$ & \\
\hline \multicolumn{3}{|l|}{ Cohabiting with } & \\
\hline partner & $450(3.5)$ & $63(3.5)$ & \\
\hline Separated & $334(2.6)$ & $41(2.3)$ & \\
\hline Widowed & $175(1.4)$ & $27(1.5)$ & \\
\hline Missing & $111(0.9)$ & $8(0.4)$ & \\
\hline Other & $40(0.3)$ & $5(0.3)$ & \\
\hline
\end{tabular}

BMI, body mass index.

*Comparison based on two-sided $z$ test for continuous data or twosided $\chi^{2}$ test for categorical data.

implants were inserted using an inframammary incision site (59.8 percent) and at a partial submuscular location (61.6 percent). The incision site differed significantly between implant types $(p<0.0001)$; the silicone-filled implants were more likely to be inserted through an inframammary incision, whereas periareolar, axillary, and periumbilical incisions-although representing a minority of cases-were more common with the saline-filled implants. Implant location also differed between implant types $(p<0.0001)$. Although most implants in both groups were placed in a partial or complete submuscular location, the silicone-filled implants were more likely to be placed in a subglandular location compared with the salinefilled implants. The vast majority of implants had a smooth surface (92.5 percent), and most ranged in size from 300 to 499 cc (76.9 percent).

\section{Satisfaction with Breasts}

The BREAST-Q scale for satisfaction with breasts was completed by 12,722 women (71.1 percent) at postoperative year 1 (11,295 women who received silicone-filled implants and 1427 women
Table 2. Lifestyle Characteristics

\begin{tabular}{|c|c|c|c|}
\hline Parameter & $\begin{array}{c}\text { Silicone- } \\
\text { Filled } \\
\text { Implants } \\
(\%)\end{array}$ & $\begin{array}{c}\text { Saline- } \\
\text { Filled } \\
\text { Implants } \\
(\%)\end{array}$ & $p^{*}$ \\
\hline No. & 12,726 & 1788 & \\
\hline Smoking history & & & $<0.0001$ \\
\hline Never smoked & $8119(63.8)$ & $1102(61.6)$ & \\
\hline Ex-smoker & $3074(24.2)$ & $395(22.1)$ & \\
\hline Current smoker & $1427(11.2)$ & $282(15.8)$ & \\
\hline Missing & $106(0.8)$ & $9(0.5)$ & \\
\hline Current smokers & & & 0.5050 \\
\hline $1-10$ cigarettes/day & $963(67.5)$ & $191(67.7)$ & \\
\hline 11-20 cigarettes/day & $383(26.8)$ & $73(25.9)$ & \\
\hline 21-30 cigarettes/day & $32(2.2)$ & $11(3.9)$ & \\
\hline $31-40$ cigarettes/day & $6(0.4)$ & $1(0.4)$ & \\
\hline Missing & $43(3.0)$ & $6(2.1)$ & \\
\hline Alcohol consumption & & & $<0.0001$ \\
\hline Never drink & $2342(18.4)$ & $392(21.9)$ & \\
\hline 1-6 drinks per mo & $6072(47.7)$ & $916(51.2)$ & \\
\hline 1-3 drinks per wk & $3058(24.0)$ & $354(19.8)$ & \\
\hline 1 drink per day & $655(5.1)$ & $58(3.2)$ & \\
\hline 2-3 drinks per day & $221(1.7)$ & $19(1.1)$ & \\
\hline$\geq 4$ drinks per day & $13(0.1)$ & $2(0.1)$ & \\
\hline Missing & $365(2.9)$ & $47(2.6)$ & \\
\hline $\begin{array}{l}\text { Previous treatment for } \\
\text { substance abuse }\end{array}$ & & & 0.0005 \\
\hline Yes & $334(2.6)$ & $46(2.6)$ & \\
\hline No & $11,820(92.9)$ & $1697(94.9)$ & \\
\hline Missing & $572(4.5)$ & $45(2.5)$ & \\
\hline
\end{tabular}

who received saline-filled implants) and by 10,420 women (58.2 percent) at postoperative year 4 (9135 and 1285, respectively). Overall, satisfaction with breasts increased significantly at postoperative year $1(p<0.0001)$, and the improvement compared with preoperative levels was sustained at year 4 $(p<0.0001)$ (Fig. 1). In the cohort who received silicone-filled breast implants, satisfaction with breasts increased by a mean of 57.5 points at postoperative year 1 (31.5 points preoperatively to 88.4 at year 1 ; $p<0.0001)$ and by 54.6 points at year 4 (31.5 points preoperatively to 86.1 at year $4 ; p<0.0001)$. Satisfaction with breasts increased by mean values of 53.0 $(p<0.0001)$ and $48.2(p<0.0001)$ at postoperative years 1 and 4 , respectively, in the cohort who received saline-filled implants. In the multivariate model, satisfaction with breasts improved significantly more in women who received silicone-filled implants compared with those who received salinefilled implants $(p<0.0001$; years 1 and 4$)$; the difference in least squares mean (silicone minus saline scores) was 1.96 (95 percent CI, 0.99 to 2.94) at year 1 and 2.09 (95 percent CI, 1.06 to 3.12) at year 4.

\section{Psychosocial Well-Being}

The psychosocial well-being scale of the BREAST-Q was completed by 12,648 women (70.7 percent) at postoperative year 1 (11,254 
Table 3. Implant Characteristics

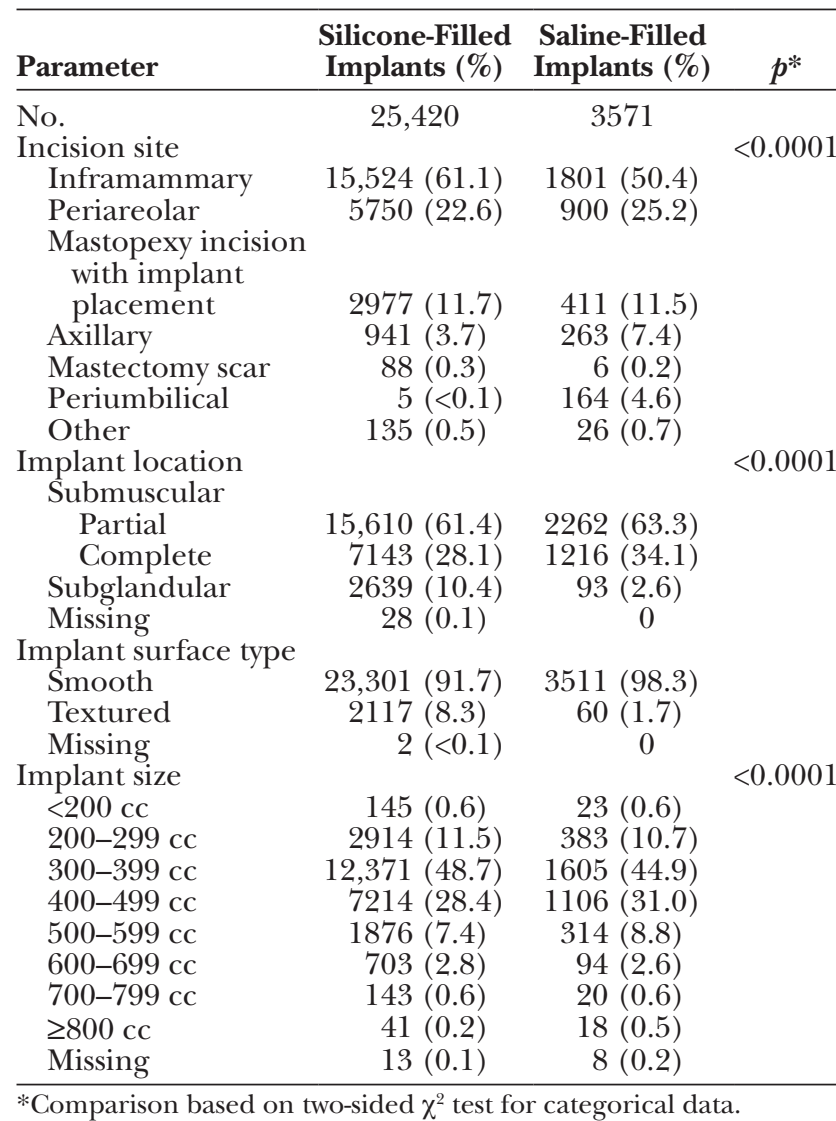

women who received silicone-filled implants and 1394 women who received saline-filled implants) and by 10,066 women ( 56.2 percent) at postoperative year 4 (8809 and 1257 women, respectively). Psychosocial well-being improved in parallel with improvements in satisfaction with breasts. Psychosocial well-being scores increased significantly compared with preoperative values at postoperative year $1(p<0.0001)$ and were sustained at year $4(p<0.0001)$ (Fig. 2). Among women receiving silicone-filled breast implants, psychosocial well-being increased by a mean of 30.2 points at postoperative year 1 (59.8 preoperatively to 89.8 at year $1 ; p<0.0001)$ and by 26.5 points at year 4 (59.8 preoperatively to 86.5 at year $4 ; p<0.0001$ ). Psychosocial well-being increased after implantation by a mean of $29.9(p<0.0001)$ at year 1 and by $26.2(p<0.0001)$ at year 4 , respectively, in women receiving saline-filled implants. In the multivariate model, psychosocial well-being improved significantly more in women who received silicone-filled implants compared with those who received salinefilled implants $(p<0.0001$, year $1 ; p<0.0019$, year $4)$; the difference in least squares mean (silicone minus saline scores) was 1.95 (95 percent CI, 1.07 to 2.82) at year 1 and 1.45 (95 percent CI, 0.53 to $2.37)$ at year 4.

\section{BREAST-Q Effect Size}

In the overall study population, breast augmentation had a large effect size for both the satisfaction with breasts and psychosocial well-being scales. Positive effect sizes of 2.0 and 1.8 were noted at postoperative years 1 and 4, respectively, for satisfaction with breasts, and effect sizes of 1.2 and 1.0 were noted at years 1 and 4, respectively, for psychosocial well-being.

\section{DISCUSSION}

The results of this study indicate that significant improvements in body image are achieved in women who undergo breast augmentation with Natrelle silicone-filled implants or saline-filled

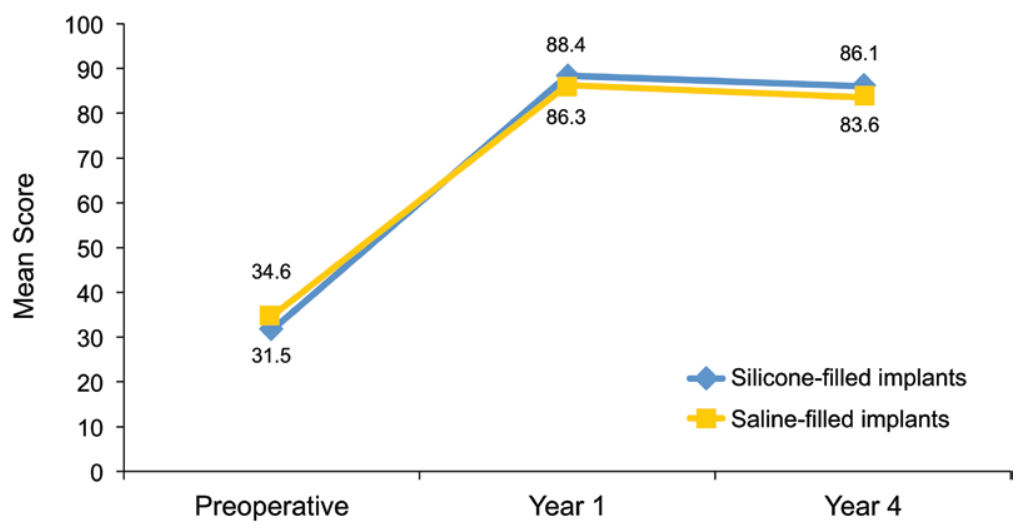

Fig. 1. Results from the BREAST-Q scale for satisfaction with breasts, measured preoperatively and at 1 and 4 years postoperatively in women who received Natrelle silicone-filled implants or saline-filled implants. Scores were transformed to a 0 - to 100 -point scale; higher scores indicate greater satisfaction. 


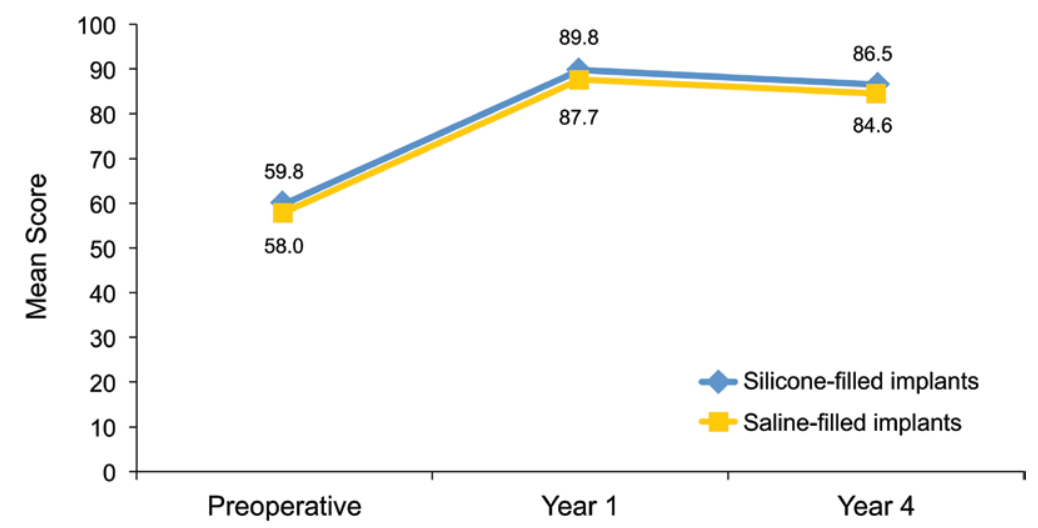

Fig. 2. Results from the BREAST-Q scale for psychosocial well-being measured preoperatively and at 1 and 4 years postoperatively in women who received Natrelle silicone-filled implants or saline-filled implants. Scores were transformed to a 0 - to 100-point scale; higher scores indicate greater psychosocial well-being.

implants. The increases in satisfaction with breasts and with psychosocial well-being were evident at postoperative year 1 and were sustained when subjects were reevaluated at year 4. Comparisons of satisfaction with breasts and psychosocial wellbeing based on the BREAST-Q scales between women who received Natrelle silicone-filled implants and those who received saline-filled implants favored the silicone-filled implants, with statistical significance between treatment groups achieved on both assessments at years 1 and 4 .

The BREAST-Q has been used previously to quantitate improvements in quality of life for women who have undergone breast augmentation. In a cohort of 639 women, of whom 73 percent received silicone-filled implants, significant improvements in satisfaction with breasts and psychosocial well-being were obtained at 6 weeks and 6 months postoperatively. ${ }^{5}$ Similar results were obtained in smaller cohorts of women who were assessed either 6 weeks postoperatively or at least 2 months postoperatively., ${ }^{3,4}$ The magnitude of the improvements at these early time points after breast augmentation were consistent with those observed in the present study at 1 and 4 years after implantation. Moreover, in the present study and in these previous smaller studies, improvements in satisfaction with breasts and in psychosocial wellbeing were associated with large effect sizes. The present study extends these earlier findings by showing that improvements in body image seen over the first months following breast augmentation remain stable over time, at least through 4 years. Before the development of the BREAST-Q survey, studies evaluating the impact of breast augmentation on quality of life used questionnaires with limited reliability. Nevertheless, these studies provided initial evidence that breast augmentation can improve a woman's satisfaction with breasts and psychosocial outcomes. ${ }^{14-17}$ The results of the current study may serve as a benchmark for quality-of-life assessments in future studies of aesthetic surgery because of the large number of subjects studied and the extended follow-up time.

The present study confirms a previous report wherein subjects were asked several questions related to satisfaction with their breasts following augmentation with Natrelle round silicone-filled implants. ${ }^{2}$ Body image was also evaluated in several ways, including the Body Esteem Scale. ${ }^{18}$ Subject satisfaction with breast size, shape, and feel improved dramatically from preoperative levels and remained high through the final assessment at 6 years after implantation. Significant improvements in body image were also observed postoperatively. In another study, satisfaction was assessed in subjects receiving Natrelle round silicone implants and Natrelle anatomically shaped form-stable silicone implants. ${ }^{6}$ Overall subject satisfaction with breasts and with breast size, shape, and feel showed significant improvement at 1 year postoperatively compared with preoperative assessments $(p<0.001$ for all). Most women in the study $(>96$ percent) were definitely or somewhat satisfied with their implants at 1 year postoperatively. Subject motivation for undergoing breast augmentation was also assessed in this study. ${ }^{6}$ Wanting to feel better about their physical appearance and improving the way they feel about themselves were key drivers for undergoing breast augmentation. Conversely, pleasing their partner and improving their sex life were not primary motivators. 
Several limitations are notable. First, the present study assessed two domains of the BREAST-Q, namely, satisfaction with breasts and psychosocial functioning. Sexual well-being and physical well-being are additional BREAST-Q domains for evaluating preoperative versus postoperative quality of life. ${ }^{10}$ Although not measured here, breast augmentation has been associated with significant improvements in sexual well-being but with small short-term decreases in physical well-being. ${ }^{4,5}$ Second, silicone-filled implants were favored compared with saline-filled implants in terms of satisfaction with breasts and psychosocial well-being. However, the large size of the study cohort, particularly for the group receiving silicone-filled implants, may have allowed relatively small between-group differences to achieve statistical significance. The statistically significant differences between groups may not necessarily predict the clinical relevance of these observations. Finally, the loss of some subjects to followup between years 1 and 4 may have influenced the study results; however, sample sizes were still large and therefore year- 4 outcomes were likely representative of the original population.

\section{CONGLUSIONS}

Augmentation with Natrelle silicone-filled breast implants or saline-filled breast implants may substantially improve a woman's satisfaction with breasts and psychosocial well-being, as documented with the reliable and validated BREAST-Q survey. These findings support the effectiveness of breast implants in improving a woman's quality of life.

Amy Alderman, M.D., M.P.H. Swan Center for Plastic Surgery 4165 Old Milton Parkway, Suite 200 East Alpharetta, Ga. 30005 amyaldermanmd@yahoo.com

\section{ACKNOWLEDGMENTS}

This study was sponsored by Allergan, Inc. (Irvine, Calif.). Writing and editorial assistance was provided to the authors by Barry Weichman, Ph.D., of Peloton Advantage (Parsippany, N.J.), and was funded by Allergan, Inc. Neither honoraria nor other forms of payment were made for authorship.

\section{REFERENCES}

1. American Society of Plastic Surgeons. 2013 plastic surgery statistics report. Available at: http:/ /www.plasticsurgery.org/
Documents / news-resources/statistics/2013-statistics / plastic-surgery-statistics-full-report-2013.pdf. Accessed April 22, 2015.

2. Murphy DK, Beckstrand M, Sarwer DB. A prospective, multicenter study of psychosocial outcomes after augmentation with natrelle silicone-filled breast implants. Ann Plast Surg. 2009;62:118-121.

3. McCarthy CM, Cano SJ, Klassen AF, et al. The magnitude of effect of cosmetic breast augmentation on patient satisfaction and health-related quality of life. Plast Reconstr Surg. 2012;130:218-223.

4. Coriddi M, Angelos T, Nadeau M, Bennett M, Taylor A. Analysis of satisfaction and well-being in the short follow-up from breast augmentation using the BREAST-Q, a validated survey instrument. Aesthet Surg J. 2013;33:245-251.

5. Alderman AK, Bauer J, Fardo D, Abrahamse P, Pusic A. Understanding the effect of breast augmentation on quality of life: Prospective analysis using the BREAST-Q. Plast Reconstr Surg. 2014;133:787-795.

6. Gladfelter J, Murphy D. Breast augmentation motivations and satisfaction: A prospective study of more than 3,000 silicone implantations. Plast Surg Nurs. 2008;28:170-174; quiz 175.

7. Centers for Devices and Radiological Health; U.S. Food and Drug Administration. FDA update on the safety of silicone gel-filled breast implants. Available at: http://www.fda.gov/downloads/MedicalDevices/ ProductsandMedicalProcedures/ImplantsandProsthetics/ BreastImplants/UCM260090.pdf. Accessed September 30, 2015.

8. Allergan, Inc. Natrelle silicone-filled breast implants smooth \& biocell texture (directions for use). Santa Barbara, Calif: Allergan; 2009.

9. Pusic AL, Klassen AF, Scott AM, Klok JA, Cordeiro PG, Cano SJ. Development of a new patient-reported outcome measure for breast surgery: The BREAST-Q. Plast Reconstr Surg. 2009;124:345-353.

10. Pusic AL, Reavey PL, Klassen AF, Scott A, McCarthy C, Cano SJ. Measuring patient outcomes in breast augmentation: Introducing the BREAST-Q Augmentation module. Clin Plast Surg. 2009;36:23-32, v.

11. Kazis LE, Anderson JJ, Meenan RF. Effect sizes for interpreting changes in health status. Med Care 1989;27 (Suppl):S178-S189.

12. Cohen J. A power primer. Psychol Bull. 1992;112:155-159.

13. Schabenberger O. Introducing the GLIMMIX procedure for generalized linear mixed models (paper 196-30). Cary, NC: SAS Institute, Inc.: 2005. Available at: http://www2.sas.com/ proceedings/sugi30/196-30.pdf. Accessed April 21, 2015.

14. Schlebusch L, Mahrt I. Long-term psychological sequelae of augmentation mammoplasty. S Afr Med J. 1993;83:267-271.

15. Young VL, Nemecek JR, Nemecek DA. The efficacy of breast augmentation: Breast size increase, patient satisfaction, and psychological effects. Plast Reconstr Surg. 1994;94:958-969.

16. Park AJ, Chetty U, Watson AC. Patient satisfaction following insertion of silicone breast implants. Br J Plast Surg. 1996;49:515-518.

17. Cash TF, Duel LA, Perkins LL. Women's psychosocial outcomes of breast augmentation with silicone gel-filled implants: A 2-year prospective study. Plast Reconstr Surg. 2002;109:2112-2121; discussion 2122.

18. Franzoi SL, Herzog ME. The Body Esteem Scale: A convergent and discriminant validity study. J Pers Assess. 1986;50:24-31. 